\title{
Carrier Dynamics Analysis in Metal-SemiconductorMetal Device for mid-IR Silicon Photonics
}

Hui, Alvin Tak Lok; Ding, Yunhong; Hu, Hao; Galili, Michael

Publication date:

2017

Document Version

Peer reviewed version

Link back to DTU Orbit

Citation (APA):

Hui, A. T. L., Ding, Y., Hu, H., \& Galili, M. (2017). Carrier Dynamics Analysis in Metal-SemiconductorMetal Device for mid-IR Silicon Photonics. Poster session presented at 2017 IEEE 14th International Conference on Group IV Photonics

, Berlin, Berlin, Germany.

\section{General rights}

Copyright and moral rights for the publications made accessible in the public portal are retained by the authors and/or other copyright owners and it is a condition of accessing publications that users recognise and abide by the legal requirements associated with these rights.

- Users may download and print one copy of any publication from the public portal for the purpose of private study or research.

- You may not further distribute the material or use it for any profit-making activity or commercial gain

- You may freely distribute the URL identifying the publication in the public portal

If you believe that this document breaches copyright please contact us providing details, and we will remove access to the work immediately and investigate your claim 


\section{Carrier Dynamics Analysis in Metal-Semiconductor- Metal Device for mid-IR Silicon Photonics}

\section{Alvin Tak Lok Hui, Yunhong Ding, Hao Hu, Michael Galili}

\begin{abstract}
A modelling platform for active carrier removal based on metal-semiconductor-metal structure is reported on analysis of carrier dynamics. The analysis reveals electric current hot spots exist in geometric singularities and curly trajectory of carriers should be considered when accurately estimating the effective carrier lifetime.
\end{abstract}

\section{BACKGROUND}

- Silicon (Si) on-chip four-wave mixing (FWM) [1]

- Limitation: two-photon absorption (TPA) and three-photon absorption (ThPA) $\rightarrow$ free carrier absorption (FCA) [2], [3]

- Metal-semiconductor-metal (MSM) structure for effective carrier removal [4], [5]

- Carrier dynamics modelling at $2 \mu \mathrm{m}$ wavelength

- Finite element modelling (COMSOL Multiphysics)

- Estimate effective carrier lifetime $\tau_{e f f}$ based on true carrier transit trajectory
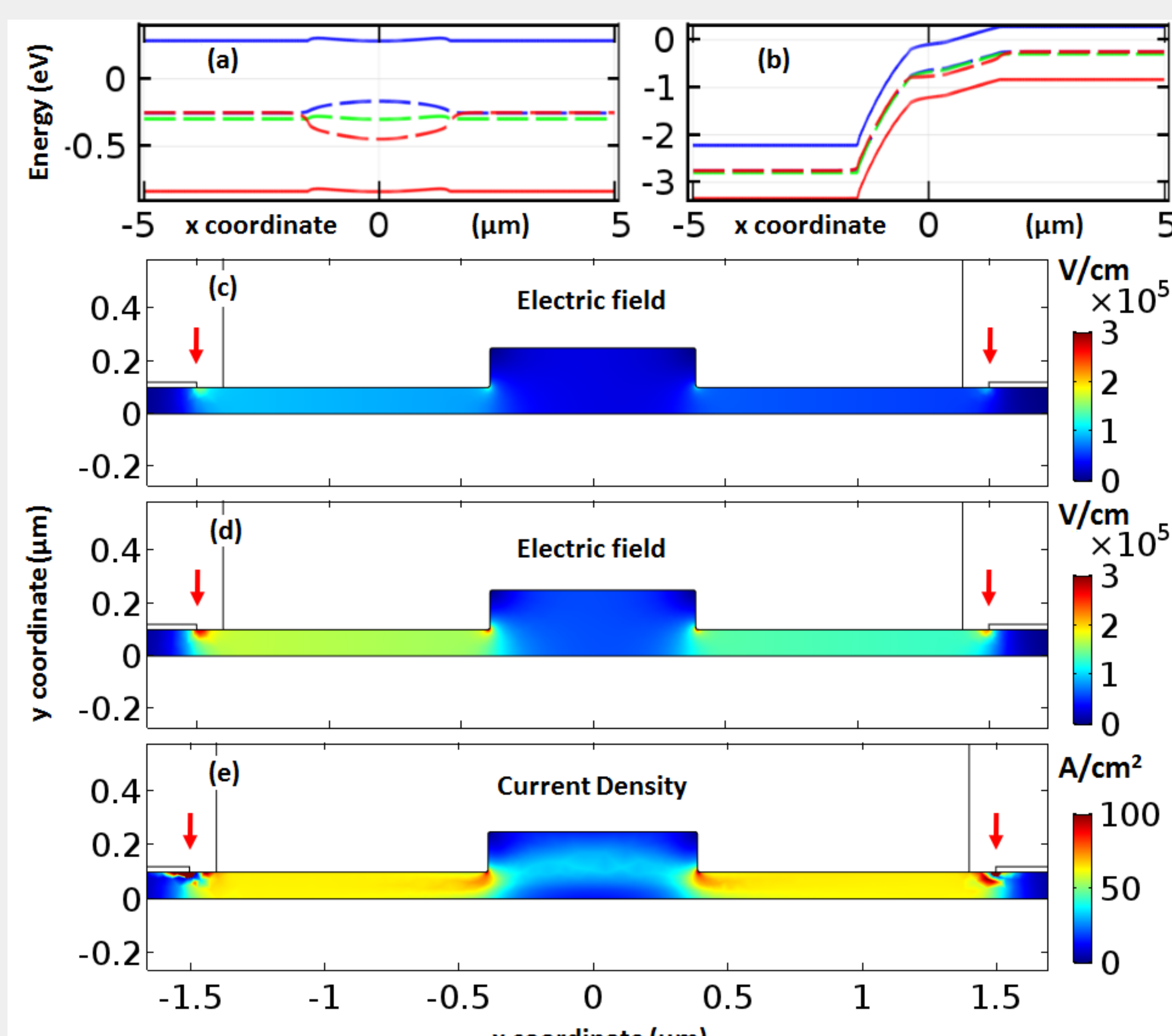

Fig. 2. Energy band diagram at (a) thermal equilibrium and (b) $2.5 \mathrm{~V}$. Electric field distribution at bias of (c) 20 and (d) $40 \mathrm{~V}$. (e) Current density corresponds to bias of $40 \mathrm{~V}$. The plots were obtained under optical power of $20 \mathrm{dBm}$.

\section{DESIGN OF DEVICE}

- Ridge waveguide on standard silicon-oninsulator (SOI) platform (250×780 nm with slab thickness of $100 \mathrm{~nm}$, p-type doping $\sim 20 \Omega \cdot \mathrm{cm}$ )

- Carrier removal by reverse biasing titanium Ti/pSi Schottky contact

- Typical Schottky barrier height of $\mathrm{Ti} \phi_{B 0}$ of 0.54 eV [6]

- Image-force barrier lowering $\Delta \phi$ is considered yielding effective barrier height of $\phi_{B 0}-\Delta \phi$ [7]

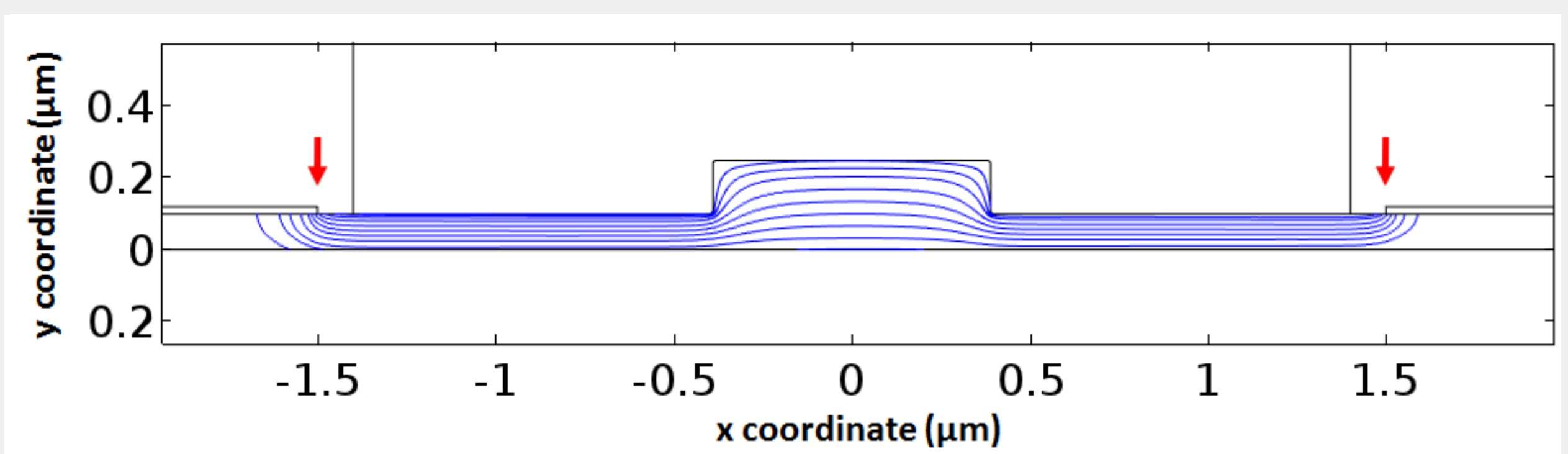

Fig. 3. Streamline plot of electric field representing the trajectory of carrier transport at bias of $10 \mathrm{~V}$ and optical power of $20 \mathrm{dBm}$. The density of streamline is proportional to the magnitude of electric field.

- Using built-in carrier mobility model to ensure carriers travel in compliance with the saturation velocity, i.e. $\sim 10^{7} \mathrm{~cm} / \mathrm{s}$ [7]

\section{CARRIER DYNAMICS}

- Under biased condition, the energy band is tilted from thermal equilibrium (Fig. $2 \mathrm{a}$ and $\mathrm{b}$ )

- By increasing the bias voltage, the depletion region penetrates into the waveguide transversely

- Presence of electric field singularities of $3 \times 10^{5} \mathrm{~V} / \mathrm{cm}$ under bias of $40 \mathrm{~V}$

- High current density $~ 3.08 \times 10^{3} \mathrm{~A} / \mathrm{cm}^{2}$ can reduce the mean-time-to-failure of the device due to electromigration and thermal stress [8]

- The approximation of straight carrier trajectories is widely adopted and yields the carrier velocity formulism [9]

$$
\tau_{1}=\frac{w_{\text {mode }}}{4}\left(\frac{1}{v_{n}}+\frac{1}{v_{p}}\right)
$$

$w_{\text {mode }}$ is the mode width;

$v_{n}$ and $v_{p}$ are the electron and hole velocities, respectively

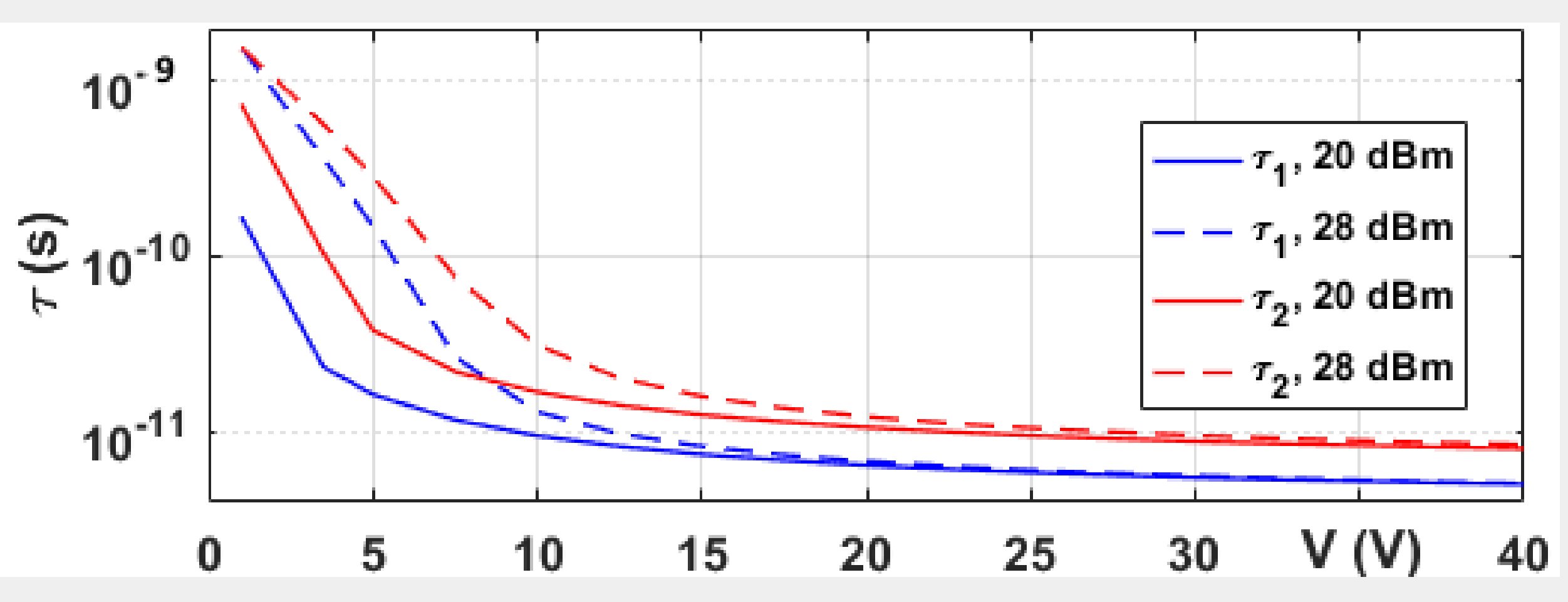

Fig. 4. Carrier lifetime of the MSM device under bias derived from formulism of carrier velocity $\tau_{1}$ and carrier density $\tau_{2}$, which correspond to Eq. (1) and (2), respectively, at moderate and high optical power levels.
- Our simulation reveals carriers does not take the straight trajectory due to the change in field distribution inside the waveguide (Fig. 3)

- Longer carrier path length is encountered $\rightarrow$ Eq. (1) underestimates $\tau_{\text {eff }}$

- Integral formulism of $\tau_{\text {eff }}$ with carrier density $N$ adopted [10] to deal with curly trajectory

$$
\tau_{2}=\frac{1}{G A_{e f f}} \oiint_{S} N d S
$$

$G$ is the photo-generation rate of free carriers $A_{e f f}$ is the effective mode area;

$S$ denotes the integration domain formed by the mode profile

- From Eq. (1), the carrier lifetime saturates at 5.1 ps under $40 \mathrm{~V}$

- From Eq. (2) considering curly trajectories, carrier lifetime saturates at 8.1 ps under $40 \mathrm{~V}$

- A better approximation of $\tau_{e f f}$ is achieved

\section{CONCLUSION}

- A carrier dynamics modelling platform has been established which facilitates the design and analysis of the MSM device towards efficient carrier removal

\section{REFERENCES}

[1] R. K. W. Lau et al., Opt. Lett., vol. 36, no. 7, pp.1263-1265 (2011)

[2] A. D. Bristow et al., Appl Phys Lett, vol. 90, no. 19, p.191104 (2007).

[3] S. Pearl et al., Appl. Phys. Lett., vol. 93, no. 13, p. 131102 (2008).

[4] C. Peucheret et al., 2014 IEEE Photonics Society Summer Topical Meeting Series, 2014, pp. 116-117.

[5] Y. Ding et al., CLEO, 2015 , paper SM1I.5.

[6] M. O. Aboelfotoh et al., Phys. Rev. B, vol. 34, no. 4, pp. 2311-2318 (1986).

[7] D. A. Neamen, Semiconductor physics and devices. McGraw-Hill (2003).

[8] J. R. Black, Proc. IEEE, vol. 57, no. 9, pp. 1587-1594 (1969).

[9] A. Gajda et al., Opt. Express, vol. 19, no. 10, pp. 9915-9922 (2011).

[10] D. Dimitropoulos et al., Appl. Phys. Lett., vol. 87 , no. 26, p.261108 (2005). 